\title{
FIXED POINT THEOREMS IN QUASI-METRIC SPACES AND THE SPECIALIZATION PARTIAL ORDER
}

\author{
NASEER SHAHZAD* AND OSCAR VALERO** \\ * Department of Mathematics, Faculty of Science \\ King Abdulaziz University, P.O. Box 80203, Jeddah 21859, Saudi Arabia \\ E-mail: nshahzad@kau.edu.sa \\ ** Departamento de Ciencias Matemáticas e Informática \\ Universidad de las Islas Baleares \\ Ctra. de Valldemossa km. 7.5, 07122 Palma de Mallorca, Spain \\ E-mail: o.valero@uib.es
}

\begin{abstract}
In this paper we present a new fixed point theorem in quasi-metric spaces which captures the spirit of Kleene's fixed point theorem. To this end, we explore the fundamental assumptions in the aforesaid result when we consider quasi-metric spaces endowed with the specialization partial order. Thus, we introduce an appropriate notion of order-completeness and order-continuity that ensure the existence of fixed point with distinguished properties. Moreover, some fixed point theorems are derived as a particular case of our main result when the self-mappings under consideration satisfy, in addition, any type of Banach contractive condition under different quasi-metric notions of completeness.
\end{abstract}

Key Words and Phrases: quasi-metric, specialization partial order, order-completeness, fixed point, monotonicity, order-continuity, contraction.

2010 Mathematics Subject Classification: 06A06, 47H09, 47H10, 54E50, 54F05, 68N30.

Acknowledgements. This project was funded by the National Plan for Science, Technology and Innovation (MAARIFAH) - King Abdulaziz City for Science and Technology - the Kingdom of Saudi Arabia - award number (12-MAT051-03). The authors also, acknowledge with thanks Science and Technology Unit, King Abdulaziz University for technical support. The authors are grateful to an anonymous referee for his useful suggestions and comments.

\section{REFERENCES}

[1] M.A. Alghamdi, N. Shahzad, O. Valero, New results on the Baire partial quasi-metric space, fixed point theory and asymtptotic complexity analysis for recursive programs, Fixed Point Theory Appl., 14(2014), 18 pp.

[2] M.A. Alghamdi, N. Shahzad, O. Valero, Fixed point theorems in generalized metric spaces with applications to computer science, Fixed Point Theory Appl., 118(2013), 20 pp.

[3] J. de Bakker, E. de Vink, Control Flow Semantics, The MIT Press, Cambridge, 1996.

[4] A. Baranga, The contraction principle as a particular case of Kleen's fixed point theorem, Discrete Math., 98(1991), 75-79. 
[5] L.J.B. Ćirić, On contraction type mappings, Math. Balkanica, 1(1971), 52-57.

[6] B.A. Davey, H.A. Priestley, Introduction to Lattices and Order, Cambridge University Press, Cambridge, 1990

[7] A. Granas, J. Dugundji, Fixed Point Theory, Springer, New York, 2002.

[8] P. Hitzler, A.K. Seda, Generalized distance functions in the theory of computation, Comput. J., 53(2010), 443-464.

[9] H.-P.A. Künzi, Nonsymmetric topology, in: Topology, János Bolyai Math. Studies, Budapest, 4(1995), 303-338.

[10] H.-P.A. Künzi, M.P. Schellekens, On the Yoneda completion of a quasi-metric space, Theoret. Comput. Sci., 278(2002), 159-194.

[11] S.G. Matthews, Partial metric topology, Ann. New York Acad. Sci., 728(1994), 183-197.

[12] J.J. Nieto, R. Rodríguez-López, Contractive mapping theorems in partially ordered sets and applications to ordinary differential equations, Order, 22(2005), 223-239.

[13] J.J. Nieto, R. Rodríguez-López, Existence and uniqueness of fixed point in partially ordered sets and applications to ordinary differential equations, Acta Math. Sinica (English Series), 23(2007), 2205-2212.

[14] I.L. Reilly, P.V. Subrahmanyam, M.K. Vamanamrthy, Cauchy sequences in quasi-pseudo-metric spaces, Monatshefte Math., 93(1982), 127-140.

[15] J.J.M.M. Rutten, Elements of generalized ultrametric domain theory, Theoret. Comput. Sci., 170(1996), 349-381.

[16] D.S. Scott, Outline of a mathematical theory of computation, in: Proc. 4th Annual Princeton Conference on Information Sciences and Systems, 1970, 169-176.

[17] D.S. Scott, Domains for denotational semantics, LNCS, 140(1982), 577-613.

[18] N. Shahzad, O. Valero, On 0-complete partial metric spaces and quantitative fixed point techniques in Denotational Semantics, Abstr. Appl. Anal., 2013(2013), Article ID 985095, 11 pages.

[19] N. Shahzad, O. Valero, M.A. Alghamdi, M.A. Alghamdi, A fixed point theorem in partial quasimetric spaces and an application to software engineering, Appl. Math. Comput., 268(2015), 1292-1301.

[20] M.B. Smyth, Quasi-uniformities: reconciling domains with metric spaces, LNCS, 298(1988), 236-253.

[21] M.B. Smyth, Totally bounded spaces and compact ordered spaces as domain of computation, in: Topology and Category Theory in Computer Science, Oxford University Press, Oxford, 1991, 207-229.

[22] M. Turinici, Abstract comparison principles and multivariable Gronwall-Bellman inequalities, J. Math. Anal. Appl., 117(1986), 100-127

[23] M. Turinici, Fixed points for monotone iteratively local contractions, Demonstr. Math. 19(1986), 171-180.

[24] G. Winskel, The Formal Semantics of Programming Langugages, The MIT Press, Cambridge, 1993.

Received: June 4, 2015; Accepted: February 25, 2016. 
